\title{
Technical Nuances of Minimal Invasive Interlaminar Decompression in Lumbar Spinal Stenosis: The Role of Minimal Invasive Bilateral Approach
}

\author{
Nicola Montano, Fabio Papacci, Fabrizio Pignotti, Eduardo Fernandez \\ Institute of Neurosurgery, Catholic University, Rome, Italy \\ Email: nicolamontanomd@yahoo.it
}

Received 22 January 2016; accepted 28 March 2016; published 31 March 2016

Copyright $@ 2016$ by authors and Scientific Research Publishing Inc.

This work is licensed under the Creative Commons Attribution International License (CC BY). http://creativecommons.org/licenses/by/4.0/

(c) (i) Open Access

\section{Abstract}

We report a series of patients operated for one or multilevel lumbar spinal stenosis (with and without spondylolisthesis) using the minimal invasive bilateral interlaminar decompression. We discuss our results, comparing this procedure (from a technical point of view) with the muscle-preserving interlaminar decompression (MILD) and the unilateral approach for bilateral decompression (ULBD). Clinical and outcome data of 62 consecutive patients were reviewed, using the Visual Analogue Scale for both low back pain (LBP) and legs pain and the Oswestry Disability Index (ODI) for the degree of disability. Mean age was $68.88 \pm 9.54$ years and mean follow-up (FU) was $16.38 \pm 11.12$ months. A statistically significant improvement of LBP, legs pain and ODI was globally observed. At latest FU, patients with multilevel lumbar spinal stenosis significantly improved all scores and patients with spondylolisthesis significantly decreased their disability. No major complications occurred. Two cerebrospinal fluid (CSF) collections were treated conservatively. No wound infection occurred. No progression of spondylolisthesis was observed. No reoperation was needed. Although efficacious in patients with lumbar spinal stenosis, MILD and ULBD can have both some limitations. MILD has been found to decrease lumbar function in multilevel decompression (increasing sagittal translation and lumbar lordosis probably due to the removal of half of the spinous processes) and ULBD shows some disadvantages due to the difficulty of manipulating instruments through a small portal and the inadequate decompression due to a minimal exposure. The minimal invasive bilateral interlaminar decompression (in this technique, the access is bilateral but the supraspinous and interspinous ligaments and the spinous processes are preserved) allows wide access (bilateral exposure) with minimal invasiveness and very low morbidity in patients with lumbar spinal stenosis at one or more levels. 


\section{Keywords}

\section{Lumbar Spinal Stenosis, Laminectomy, Spine, Spondylolisthesis, Minimal Invasive Approach, Interlaminar Decompression}

\section{Introduction}

Symptomatic lumbar spinal stenosis is the most common condition leading to decompressive surgery. The most common technique is open laminectomy [1]-[3], which has been shown to improve quality-of-life outcomes compared to conservative therapy [4]-[6]. Nonetheless, this procedure can be associated to iatrogenic instability requiring reoperation to perform lumbar fusion by instrumentation [7]. Minimal invasive procedures such as the muscle-preserving interlaminar decompression (MILD) [8] and the unilateral approach for bilateral decompression (ULBD) [9] have been reported in the literature [10]-[12] as alternative techniques for lumbar spinal stenosis decompression. These techniques are both efficacious to treat patients with single level spinal stenosis [11]. Moreover, in a recent randomized trial [12] and in a recent systematic review [13], it has been evidenced that ULBD is as effective as open laminectomy in improving clinical functional outcome, with the additional benefits of a significantly greater decrease in pain, postoperative recovery time, time to mobilization and opioid use. Nonetheless, both the minimal invasive approaches have some limitations. MILD has been found to increase sagittal translation and lumbar lordosis in multilevel decompression, probably due to the removal of half of the spinous processes [10] and ULBD can show some disadvantages such as the difficulty of manipulating instruments through a small portal and the inadequate decompression due to a minimal exposure [12]. Here we report the results of a series of patients operated at one or multilevel lumbar spinal stenosis (with and without spondylolisthesis), using the minimal invasive bilateral interlaminar decompression [14], in which the access was bilateral but the supraspinous and interspinous ligaments and the spinous processes were preserved. We also discuss our results taking into account the pertinent literature.

\section{Methods}

\subsection{Patients}

We retrospectively reviewed clinical and outcome data of 62 consecutive patients (31 M, 31 F) submitted to minimal invasive bilateral interlaminar decompression for the treatment of lumbar spinal stenosis at one or more levels, from September 2011 to April 2015, at the Institute of Neurosurgery, Catholic University, Rome. All patients signed a written informed consent. The mean age was $68.88 \pm 9.54$ years. The mean follow-up (FU) was $16.38 \pm 11.12$ months. All patients had no previous lumbar spine operation and complained of lumbar/legs pain and/or neurogenic claudication unresponsive to conservative (physical and medical) treatment for at least 1 year, with a magnetic resonance imaging (MRI), showing a lumbar spinal stenosis at one or more levels. Patients with an associated spondylolisthesis grade I were included in this study. Patients were submitted pre-operatively and at FU to lumbar spine MRI and X-ray (anterior-posterior, lateral neutral and lateral flexion/extension projections). The changes about pain were assessed using the Visual Analogue Scale (VAS) for both low back pain (LBP) and legs pain. The Oswestry Disability Index (ODI) was used to evaluate the degree of disability of these patients. All scores were evaluated pre-operatively, one day post-operatively and at latest FU for each patient. Statistical comparison of continuous variables and ordinal variables was performed by the t-Student test and by Wilcoxon signed rank test, as appropriate.

\subsection{Surgical Technique [14]}

Under general anesthesia and in prone position, the correct level of surgery was confirmed using intraoperative imaging. A midline skin incision was made to expose the fascia. Fascia was incised bilaterally with the supraand interspinous ligaments and the spinous processes preserved. The paraspinous muscles were stripped on both sides from the laminae and the capsules of the facet joints. Under microscopic view, a little rim of bone from the caudal aspect of the cranial lamina and the cranial aspect of the caudal lamina was removed, thereby creating a larger interlaminar space. The ligamentum flavum was removed bilaterally, and the spinal recess subsequently 
was opened bilaterally by undercutting minimal portions of the medial facet joints. At the end of the procedure, the dural sac and the nerve root were decompressed bilaterally. Two illustrative cases are presented in Figure 1 and Figure 2.

\section{Results}

Clinical and outcome data of patients are summarized in Table 1. We globally found a statistically significant improvement of post-operative LBP compared to pre-operative (VAS; pre-operative $7.24 \pm 2.62$, post-operative $3.96 \pm 2.26$; $p$ < 0.0001; Figure 3). At FU LBP (VAS; $2.75 \pm 2.95$; Figure 3) was significantly reduced compared to pre-operative $(\mathrm{p}<0.0001)$ and post-operative $(\mathrm{p}=0.0002)$. Post-operative legs pain was also significantly improved compared to pre-operative (VAS; pre-operative $8.08 \pm 1.95$, post-operative $3.88 \pm 2.38$; $\mathrm{p}<$ 0.0001; Figure 4). At FU, legs pain (VAS; $2.80 \pm 3.26$, Figure 4) was significantly decreased compared to pre-operative $(\mathrm{p}<0.0001)$ and post-operative $(\mathrm{p}=0.0007)$. Considering the degree of disability we observed a

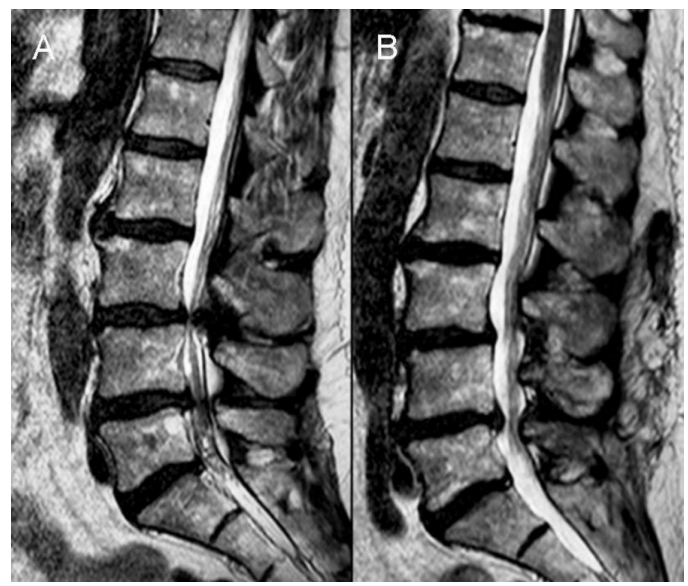

Figure 1. (A) Pre-operative T2-weighted sagittal spinal lumbar MRI of a 65 year-old man with a L3-L4 and L4-L5 stenosis. The patient was submitted to bilateral interlaminar decompression at these levels. (B) One year FU T2-weighted sagittal spinal lumbar MRI showing the optimal decompression of dural sac and nerve roots.

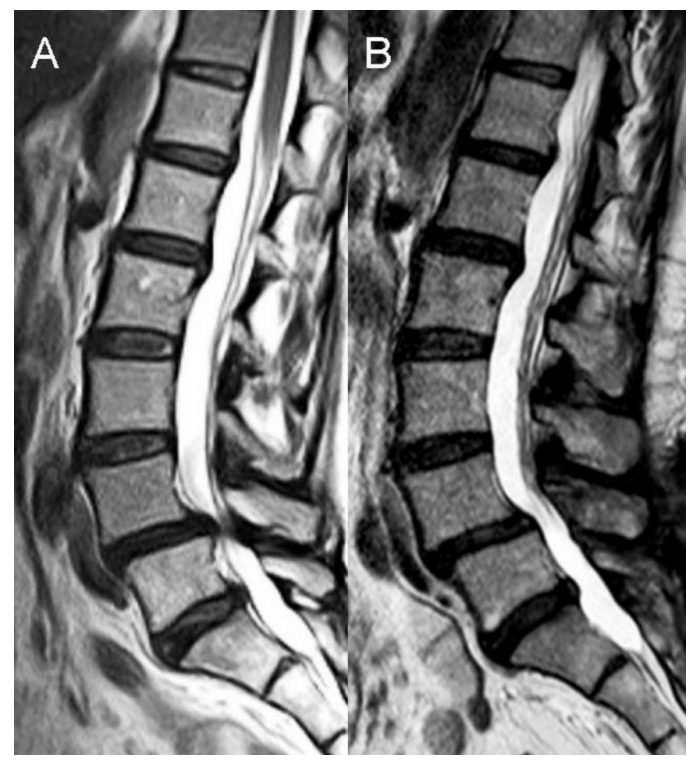

Figure 2. (A) Pre-operative T2-weighted sagittal spinal lumbar MRI of a 60 year-old woman with a L4-L5 stenosis and spondylolisthesis. The patient was submitted to bilateral interlaminar decompression at this level. (B) One year FU T2weighted sagittal spinal lumbar MRI showing the optimal decompression of dural sac and nerve roots with no progression of spondylolisthesis. 
Table 1. Clinical and outcome data of 62 patients submitted to minimal invasive bilateral interlaminar decompression for lumbar spinal stenosis, from September 2011 to April 2015, at Catholic University, Rome.

\begin{tabular}{cc}
\hline Patients & 62 \\
\hline Sex (M/F) & $31 / 31$ \\
Mean age (years) & $68.88 \pm 9.54$ \\
Level number (1/2/3/4) & $23 / 28 / 10 / 1$ \\
Spondylolisthesis (Yes/Not) & $7 / 55$ \\
\hline Low back pain VAS & $7.24 \pm 2.62$ \\
\hline Pre-operative & $3.96 \pm 2.26$ \\
Post-operative & $2.75 \pm 2.95$ \\
\hline At follow-up & \\
\hline Legs pain VAS & $8.08 \pm 1.95$ \\
\hline Pre-operative & $3.88 \pm 2.38$ \\
Post-operative & $2.80 \pm 3.26$ \\
\hline At follow-up & \\
\hline Oswestry Disability Index (\%) & $59.03 \pm 11.98$ \\
\hline Pre-operative & $22.64 \pm 17.61$ \\
Post-operative & $16.51 \pm 16.24$ \\
At follow-up & $16.38 \pm 11.12$ \\
\hline Mean follow-up (months) & \\
\hline
\end{tabular}

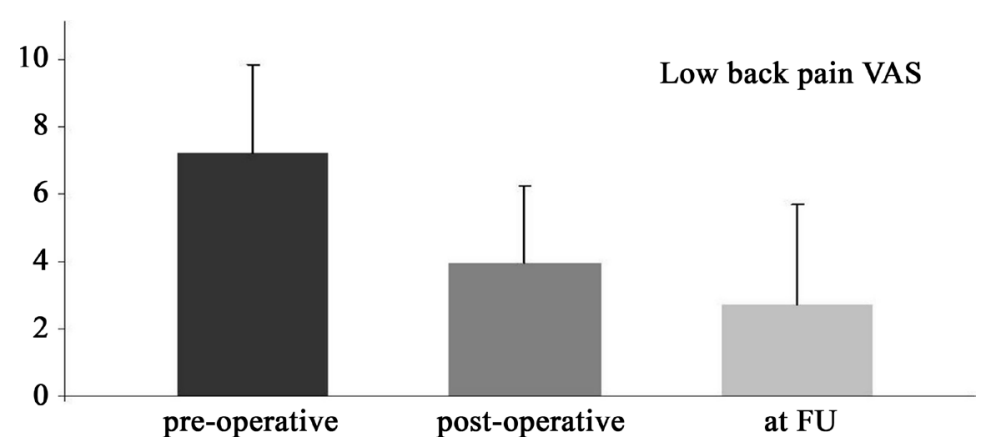

Figure 3. Bar graph. Pre-operative, post-operative and follow-up (FU) low back pain VAS of 62 patients submitted to bilateral interlaminar decompression for lumbar spinal stenosis showing the statistically significant improvement of VAS at latest FU. Error bars indicate deviation standard.

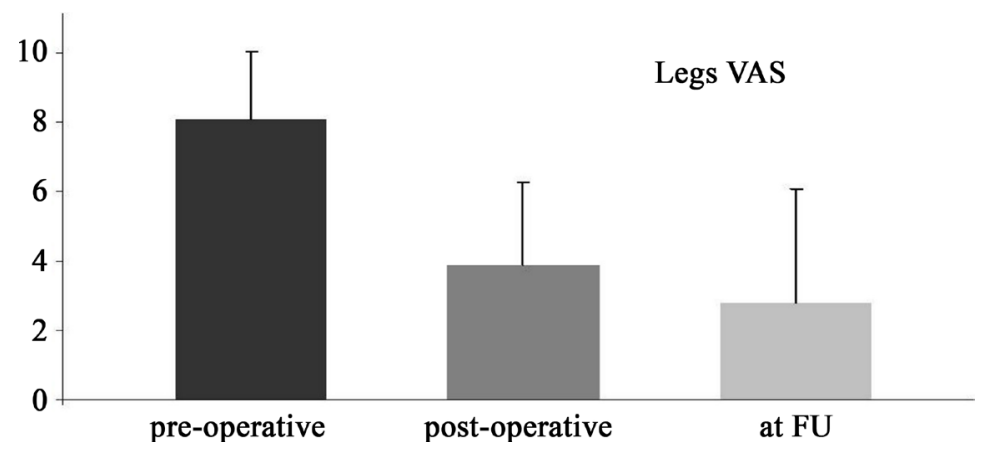

Figure 4. Bar graph. Pre-operative, post-operative and follow-up (FU) legs pain VAS of 62 patients submitted to bilateral interlaminar decompression for lumbar spinal stenosis showing the statistically significant improvement of VAS at latest FU. Error bars indicate deviation standard. 
statistically significant improvement of post-operative ODI compared to pre-operative (\%; pre-operative $59.03 \pm$ 11.98, post-operative $22.64 \pm 17.61$; $>0.0001$; Figure 5). The ODI at FU (\%; $16.51 \pm 16.24$; Figure 5) was significantly better than pre-operative $(\mathrm{p}<0.0001)$ and post-operative $(\mathrm{p}<0.0001)$. At latest FU patients operated at more than one level experienced a statistically significant improvement of low back pain (VAS; pre-operative $7.38 \pm 2.54$, at FU $3.15 \pm 3.03$; p < 0.0001) legs pain (VAS; pre-operative $8.12 \pm 2.00$, at FU $3.05 \pm 3.34 ; \mathrm{p}<$ $0.0001)$ and ODI (\%; pre-operative $61.12 \pm 11.12$, at FU $17.53 \pm 16.69$; $\mathrm{p}<0.0001$ ) with no differences compared to patients operated at one level. Patients with spondylolisthesis experienced a statistically significant improvement of their disability at latest FU (ODI; \%; pre-operative $59.71 \pm 15.07$, at FU $26.28 \pm 22.28$; p = 0.0178). Mean operation length was $116.93 \pm 39.42$ minutes $(89.13 \pm 35.85$ and $133.33 \pm 31.73$ minutes for one level and more than one level, respectively). No major complications occurred post-operatively and at FU. Two cerebrospinal fluid (CSF) collections were treated conservatively and resolved in one week. No wound infection occurred. At latest FU, no progression of spondylolisthesis was observed. No reoperation was needed.

\section{Discussion}

Lumbar spinal stenosis can cause progressive neurogenic claudication, radicular pain, and weakness. In multiple randomized and nonrandomized trials, it has been evidenced that, when symptoms are present, surgical decompression can improve quality-of-life outcomes [4]-[6]. However, there is no consensus about the optimal surgical technique. The most common approach is an open laminectomy with medial facetectomy and foraminotomy [1]-[3], which provides wide decompression but involves wide muscle retraction and extensive removal of posterior spinal structures, which can lead to lumbar instability [15]. Indeed, a recent systematic review established that iatrogenic spondylolisthesis following laminectomy is a common condition often requiring reoperation for the instability [7]. Thus lumbar fusion with instrumentation is commonly used following decompression for stenosis associated with spondylolisthesis [16]. Nonetheless, instrumentation has been associated to a number of complications such as increase of low back pain, fracture of the vertebral body and the pedicle, pedicle screw loosening and adjacent segment degeneration [17]. There is evidence that fusion may increase the biomechanical stress imposed on the adjacent segments, leading to overload disease [18] and requiring secondary spine surgery for lumbar adjacent instability [19]. To overcome these problems, minimal invasive procedures have been reported in the literature [10]-[14]. The most common minimal invasive approaches are: the muscle-preserving interlaminar decompression (MILD), introduced by Hatta et al. [8] and the unilateral approach for bilateral decompression (ULBD), reported by Spetzger et al. [9]. Briefly, in the first procedure [8], the supraspinous ligament is longitudinally split down the middle, and both the caudal part of the upper adjacent spinous process and the cranial part of the lower adjacent spinous process are exposed by detaching the supraspinous ligament. The exposed portions of the spinous processes are removed with the cranial third of the lower adjacent lamina, to free the caudal margin of the ligamentum flavum. After partial laminotomy of the caudal half of the upper adjacent lamina, a dome-like expansion is performed by removing the inner laminar plate to the extent that the cranial margin of the ligamentum flavum is freed. The bilateral facet joint is undercut to expose the lateral margin of the ligamentum flavum, that is then easily removed. In the ULBD technique [9], the supraspinous and interspinous

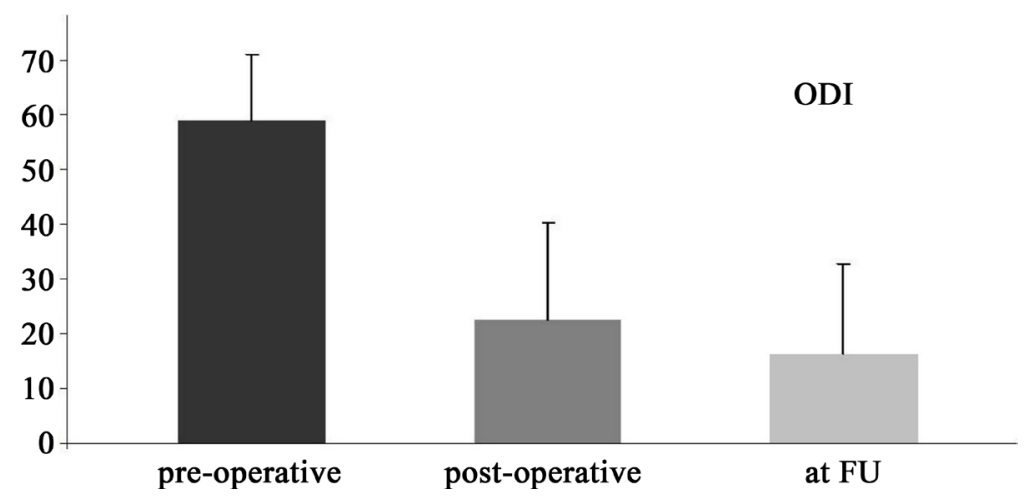

Figure 5. Bar graph. Pre-operative, post-operative and follow-up (FU) ODI of 62 patients submitted to bilateral interlaminar decompression for lumbar spinal stenosis showing the statistically significant improvement of ODI at latest FU. Error bars indicate deviation standard. 
ligaments are preserved during the surgical procedure and the spine is usually approached from the most symptomatic side. After the paraspinal muscles are dissected from the midline, the interlaminar space is exposed. Under microscopic view, laminotomy is performed by removing a portion of the superior and inferior lamina at the segment, as well as a small portion of the medial facet. The ligamentum flavum and its bony attachments are removed to expose the dural sac. After the first laminotomy is performed on one side, the deep cortical surface of the contralateral lamina is undercut, and drilling is extended to the contralateral lateral recess, permitting the removal of the ligamentum flavum. It has been reported the usefulness of both procedures to treat patients with single level spinal stenosis [11]. In a recent prospective study, in patients with multilevel decompression, UBLD was found superior to MILD in term of low back pain and lumbar function (increased sagittal translation and lumbar lordosis in MILD compared to UBLD, probably due to the removal of half of the spinous processes in the MILD) [10]. Nonetheless, Mobbs et al. [12] reported that UBLD can have some disadvantages such as the difficulty of manipulating instruments through a small portal (resulting in a more significant dural sac retraction and a higher possibility of dural tears) and the higher recurrence and reoperation rates due to minimal exposure, leading to inadequate decompression [12]. The minimal invasive bilateral interlaminar decompression [14] allows wide access (bilateral exposure) with minimal invasiveness (the supra- and interspinous ligaments and the spinous processes are preserved). In our study we found a statistically significant improvement of all clinical parameters at FU with a very low morbidity. This data is particularly significant, taking into account that the majority of our population was composed of elderly patients $(58.06 \%$ of patients with age $\geq 70$ years and $32.25 \%$ of patients with age $\geq 75$ years). Moreover we observed no progression of spondylolisthesis and no need of reoperation at latest $\mathrm{FU}$.

\section{Conclusion}

Our study has some limitations due to the retrospective nature of data. Nonetheless, we think that this technique provides good results in terms of wide exposure and minimal invasiveness with very low morbidity in patients with lumbar spinal stenosis at one or more levels.

\section{References}

[1] Bouras, T., Stranjalis, G., Loufardaki, M., Sourtzis, I., Stavrinou, L.C. and Sakas, D.E. (2010) Predictors of Long-Term Outcome in an Elderly Group after Laminectomy for Lumbar Stenosis. Journal of Neurosurgery: Spine, 13, 329-334. http://dx.doi.org/10.3171/2010.3.SPINE09487

[2] Cavuşoğlu, H., Türkmenoğlu, O., Kaya, R.A., Tuncer, C., Colak, I., Sahin, Y. and Aydin, Y. (2007) Efficacy of Unilateral Laminectomy for Bilateral Decompression in Lumbar Spinal Stenosis. Turkish Neurosurgery, 17, 100-108.

[3] Mariconda, M., Fava, R., Gatto, A., Longo, C. and Milano, C. (2002) Unilateral Laminectomy for Bilateral Decompression of Lumbar Spinal Stenosis: A Prospective Comparative Study with Conservatively Treated Patients. Journal of Spinal Disorders \& Techniques, 15, 39-46. http://dx.doi.org/10.1097/00024720-200202000-00006

[4] Atlas, S.J., Deyo, R.A., Keller, R.B., Chapin, A.M., Patrick, D.L., Long, J.M. and Singer, D.E. (1996) The Maine Lumbar Spine Study, Part III. 1-Year Outcomes of Surgical and Nonsurgical Management of Lumbar Spinal Stenosis. Spine, 21, 1787-1795. http://dx.doi.org/10.1097/00007632-199608010-00012

[5] Malmivaara, A., Slätis, P., Heliövaara, M., Sainio, P., Kinnunen, H., Kankare, J., Dalin-Hirvonen, N., Seitsalo, S., Herno, A., Kortekangas, P., Niinimäki, T., Rönty, H., Tallroth, K., Turunen, V., Knekt, P., Härkänen, T. and Hurri, H. (2007) Finnish Lumbar Spinal Research Group: Surgical or Nonoperative Treatment for Lumbar Spinal Stenosis? A Randomized Controlled Trial. Spine, 32, 1-8. http://dx.doi.org/10.1097/01.brs.0000251014.81875.6d

[6] Weinstein, J.N., Tosteson, T.D., Lurie, J.D., Tosteson, A.N., Blood, E., Hanscom, B., Herkowitz, H., Cammisa, F., Albert, T., Boden, S.D., Hilibrand, A., Goldberg, H., Berven, S. and An, H. (2008) SPORT Investigators: Surgical versus Nonsurgical Therapy for Lumbar Spinal Stenosis. The New England Journal of Medicine, 358, 794-810. http://dx.doi.org/10.1056/NEJMoa0707136

[7] Guha, D., Heary, R.F. and Shamji, M.F. (2015) Iatrogenic Spondylolisthesis Following Laminectomy for Degenerative Lumbar Stenosis: Systematic Review and Current Concepts. Neurosurgical Focus, 39, E9. http://dx.doi.org/10.3171/2015.7.FOCUS15259

[8] Hatta, Y., Shiraishi, T., Sakamoto, A., Yato, Y., Harada, T., Mikami, Y., Hase, H. and Kubo, T. (2009) Muscle-Preserving Interlaminar Decompression for the Lumbar Spine: A Minimally Invasive New Procedure for Lumbar Spinal Canal Stenosis. Spine, 34, E276-E280. http://dx.doi.org/10.1097/BRS.0b013e318195d943

[9] Spetzger, U., Bertalanffy, H., Reinges, M.H. and Gilsbach, J.M. (1997) Unilateral Laminotomy for Bilateral Decom- 
pression of Lumbar Spinal Stenosis. Part II: Clinical Experiences. Acta Neurochirurgica, 139, 397-403. http://dx.doi.org/10.1007/BF01808874

[10] Arai, Y., Hirai, T., Yoshii, T., Sakai, K., Kato, T., Enomoto, M., Matsumoto, R., Yamada, T., Kawabata, S., Shinomiya, K. and Okawa, A. (2014) A Prospective Comparative Study of 2 Minimally Invasive Decompression Procedures for Lumbar Spinal Canal Stenosis: Unilateral Laminotomy for Bilateral Decompression (ULBD) versus Muscle-Preserving Interlaminar Decompression (MILD). Spine, 39, 332-340. http://dx.doi.org/10.1097/BRS.0000000000000136

[11] den Boogert, H.F., Keers, J.C., Marinus Oterdoom, D.L. and Kuijlen, J.M. (2015) Bilateral versus Unilateral Interlaminar Approach for Bilateral Decompression in Patients with Single-Level Degenerative Lumbar Spinal Stenosis: A Multicenter Retrospective Study of 175 Patients on Postoperative Pain, Functional Disability, and Patient Satisfaction. Journal of Neurosurgery: Spine, 23, 326-335. http://dx.doi.org/10.3171/2014.12.SPINE13994

[12] Mobbs, R.J., Li, J., Sivabalan, P., Raley, D. and Rao, P.J. (2014) Outcomes after Decompressive Laminectomy for Lumbar Spinal Stenosis: Comparison between Minimally Invasive Unilateral Laminectomy for Bilateral Decompression and Open Laminectomy. Journal of Neurosurgery: Spine, 21, 179-186. http://dx.doi.org/10.3171/2014.4.SPINE13420

[13] Phan, K. and Mobbs, R.J. (2015) Minimally Invasive versus Open Laminectomy for Lumbar Stenosis-A Systematic Review and Meta-Analysis. Spine, 41, E91-E100. http://dx.doi.org/10.1097/BRS.0000000000001161

[14] Thomé, C., Zevgaridis, D., Leheta, O., Bäzner, H., Pöckler-Schöniger, C., Wöhrle, J. and Schmiedek, P. (2005) Outcome after Less-Invasive Decompression of Lumbar Spinal Stenosis: A Randomized Comparison of Unilateral Laminotomy, Bilateral Laminotomy, and Laminectomy. Journal of Neurosurgery: Spine, 3, 129-141. http://dx.doi.org/10.3171/spi.2005.3.2.0129

[15] Khoo, L.T. and Fessler, R.G. (2002) Microendoscopic Decompressive Laminotomy for the Treatment of Lumbar Stenosis. Neurosurgery, 51, S146-S154. http://dx.doi.org/10.1097/00006123-200211002-00020

[16] Resnick, D.K., Choudhri, T.F., Dailey, A.T., Groff, M.W., Khoo, L., Matz, P.G., Mummaneni, P., Watters 3rd, W.C., Wang, J., Walters, B.C. and Hadley, M.N. (2005) American Association of Neurological Surgeons/Congress of Neurological Surgeons: Guidelines for the Performance of Fusion Procedures for Degenerative Disease of the Lumbar Spine. Part 9: Fusion in Patients with Stenosis and Spondylolisthesis. Journal of Neurosurgery: Spine, 2, 679-685. http://dx.doi.org/10.3171/spi.2005.2.6.0679

[17] Shono, Y., Kaneda, K., Abumi, K., McAfee, P.C. and Cunningham, B.W. (1998) Stability of Posterior Spinal Instrumentation and Its Effects on Adjacent Motion Segments in the Lumbosacral Spine. Spine, 23, 1550-1558. http://dx.doi.org/10.1097/00007632-199807150-00009

[18] Lee, J.C. and Choi, S.W. (2015) Adjacent Segment Pathology after Lumbar Spinal Fusion. Asian Spine Journal, 9, 807-817.http://dx.doi.org/10.4184/asj.2015.9.5.807

[19] Chen, W.J., Lai, P.L., Niu, C.C., Chen, L.H., Fu, T.S. and Wong, C.B. (2001) Surgical Treatment of Adjacent Instability after Lumbar Spine Fusion. Spine, 26, E519-E524. http://dx.doi.org/10.1097/00007632-200111150-00024 